\title{
VERIFIKASI DESAIN ANTENA BERBASIS DIPOL BERBENTUK V UNTUK PENGAMATAN GARIS 21 CM
}

\section{DESIGN VERIFICATION OF V-SHAPE DIPOLE-BASED ANTENNA FOR 21 CM OBSERVATIONS}

\author{
Radial Anwar1, Mohammad Tariqul Islam², Norbahiah Misran², Asnor Nadirah Ishak ${ }^{3}$, \\ Baharudin Yatim ${ }^{4}$, Mhd Fairos Asillam ${ }^{5}$ \\ 1Program Studi Teknik Telekomunikasi, Falkutas Ilmu Terapan, Telkom University, 40257, Bandung, \\ Indonesia \\ 2Jabatan Kejuruteraan Elektrik, Elektronik \& Sistem, Fakulty Kejuruteraan dan Alam Bina, Universiti \\ Kebangsaan Malaysia, 43600 UKM Bangi, Selangor, Malaysia \\ 3Agensi Angkasa Negara Malaysia (ANGKASA), Lot 2233, Jalan Turi, Kpg. Sg. Lang, 42700 Banting, \\ Selangor, Malaysia \\ 4Pusat Pengajian Fizik Gunaan, Fakulti Sains dan Teknologi, Universiti Kebangsaan Malaysia, 43600, \\ Selangor, Malaysia \\ 5Agensi Angkasa Negara Malaysia (ANGKASA), Planetarium Negara Malaysia, Jalan Perdana, Tasik \\ Perdana, 50480 Kuala Lumpur, Wilayah Persekutuan Kuala Lumpur, Malaysia \\ 1radialanwar@tass.telkomuniversity.ac.id, 2titareq@gmail.com, 3bahiah@eng.ukm.my, \\ 4asnor@angkasa.gov.my, ${ }^{5}$ baha@ukm.my, ${ }^{6}$ fairos@angkasa.gov.my.
}

\begin{abstract}
Abstrak
$21 \mathrm{~cm}$ adalah salah satu garis emisi penting didalam astronomi radio. Garis ini umumnya digunakan untuk mempelajari karakteristik galaksi-galaksi. Artikel ini mempresentasikan sebuah antena dipol berbentuk $\mathrm{V}$ untuk sistem telekop radio $21 \mathrm{~cm}$, yang berkorespondensi dengan frekuensi pengamatan $1420 \mathrm{MHz}$. Designnya telah diimplementasikan dan diukur. Hasil pengukuran memperlihatkan kesesuaian dengan simulasi, dengan eror frekuensi puncak sebesar $0,7 \%$. SWR yang diperoleh juga cukup rendah, yaitu sekitar 1,14. Antena yang diajukan pada artikel ini berpotensi untuk digunakan sebagai feed pada antena reflektor atau sebagai elemen penyusun pada sebuah sistem antena array.
\end{abstract}

Kata Kunci : $21 \mathrm{~cm}$, antena dipol, bentuk V, astronomi radio

\section{Abstract}

$21 \mathrm{~cm}$ is one among important emission lines in radio astronomy. It is used mostly for study on galaxies property. In this paper, a V-shape dipole antenna is presented for $21 \mathrm{~cm}$ radio telescope system, which is corresponding to $1420 \mathrm{MHz}$ observation frequency. The design has been constructed and measured. It shows a good agreement with simulation results, with frequency peak error of about $0.7 \%$. The obtained SWR is relatively low, of about 1.14 . The proposed antenna has the potential to be utilized as a feed in reflector antenna or as elements in an array antenna system.

Keywords: $21 \mathrm{~cm}$, dipole antenna, V-shape, radio astronomy

\section{PENDAHULUAN}

Astronomi radio adalah salah satu cabang dibidang astronomi dimana pengamatan dilakukan pada panjang gelombang radio. Banyak hal baru dibidang astronomi yang ditemukan melalui pengamatan radio [1]. Intrumen yang digunakan disebut sebagai teleskop radio, yaitu 
suatu sistem yang menyerupai perangkat penerima pada sistem telekomunikasi, meliputi antena, filter, amplifier, dan detektor. Walaupun hanya bersifat sebagai penerima (passive service), radio teleskop umumnya dioperasikan hanya pada frekuensi tertentu yang dilindungi oleh International Telecommunication Union (ITU) [2] bagi kepentingan radio astronomi, untuk menghindari interferensi dari sinyal telekomunikasi. Untuk alasan yang sama, banyak juga teleskop radio yang dibangun di daerah yang jauh dari pusat keramaian atau di daerah-daerah terpencil.

Salah satu pengamatan yang sering dilakukan oleh astronom radio adalah observasi pada panjang gelombang $21 \mathrm{~cm}$, yang berkorespondensi dengan frekuensi $1420 \mathrm{MHz}$. Pada panjang gelombang ini, yang diamati adalah distribusi atom hidrogen netral pada galaksi tertentu, untuk mempelajari struktur galaksi, mengukur kecepatan Local Group Standard [3], atau bahkan untuk mengukur massa Neutrino [4]. Semua penelitian tersebut tidak dapat diamati pada panjang gelombang optik atau gelombang elektromagnetik lainnya dan hanya dapat dipelajari melalui astronomi radio.

Antena merupakan salah satu komponen teleskop radio yang telah menjadi suatu topik penelitian yang menarik. Berbagai jenis antena dapat dan telah digunakan sebagai bagian dari suatu sistem telekop radio, meliputi antena parabola (reflector) [5], horn [6], helix [7], maupun antena berbasis dipol [8-10]. Artikel ini akan membahas verifikasi desain sebuah antena berbasis dipol berbentuk V dengan frekuensi kerja pada $1420 \mathrm{MHz}$. Desain dan studi parameter antena melalui simulasi telah dijabarkan pada [11]. Artikel ini akan memberikan hasil konstruksi, pengukuran dan uji coba antena yang diusulkan.

\section{ARSITEKTUR ANTENA}

Antena berbasis dipol berbentuk $\mathrm{V}$ telah digunakan pada [9-10], namun pada frekuensi kerja yang lebih rendah. Pemilihan geometri dasar berbentuk $\mathrm{V}$ memungkinkan analisis geometri antena pada posisi yang lebih dekat dengan permukaan tanah, memperoleh pola radiasi yang lebih lebar dengan gain tertinggi pada arah zenit, serta VSWR yang relatif rendah untuk saluran transmisi $50 \mathrm{ohm}$. Gambar 1 memperlihatkan geometri umum antena berbentuk V, sedangkan parameternya antena yang diusulkan disajikan pada Tabel 1.

Tiga parameter telah divariasikan untuk melihat perubahan pada karakteristik antena. Parameter tersebut adalah panjang lengan dipol atau elemen yang dicatu (w), sudut antara lengan dipol $(\theta)$ dan tinggi titik terminal dari tanah $(H)$. Sudut divariasikan dari $60^{\circ}$ sampai $180^{\circ}$ dengan interval $10^{\circ}$, sedangkan ketinggian diubah-ubah pada $\lambda / 4, \lambda / 6$, dan $\lambda / 8$. Oleh karena itu, panjang lengan telah dioptimalkan melalui 39 kombinasi parameter. Sudut yang lebih rendah dari $60^{\circ}$ tidak diamati karena secara teoritis akan memiliki Standing Wave Ratio (SWR) yang tinggi, sedangkan sudut yang lebih besar dari $180^{\circ}$ berimplikasi bahwa antena sudah berubah menjadi bentuk Inverted-V. Adapun ketinggian $\lambda / 4$ sampai dengan $\lambda / 8$ dipilih karena secara teoritis akan memberikan penguatan (gain) maksimum pada arah zenit, karakteristik yang penting untuk antena pada sistem teleskop radio.

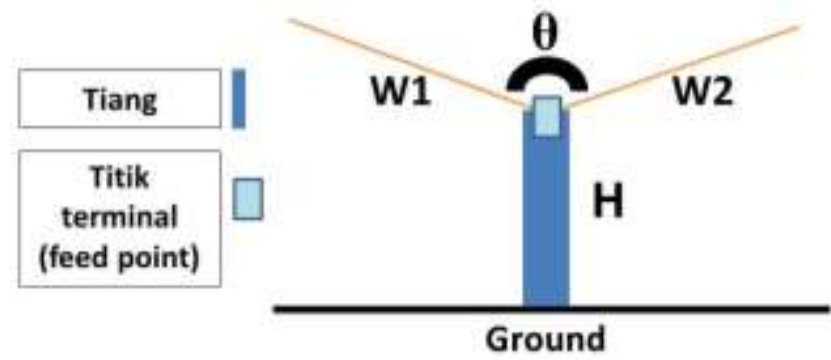

Gambar 1. Geometri antena berbentuk V 
Tabel 1. Parameter antena yang diusulkan

\begin{tabular}{|l|l|}
\hline \multicolumn{1}{|c|}{ Parameter } & \multicolumn{1}{c|}{ Nilai } \\
\hline Tinggi antena $(\mathrm{H})$ & $3,5 \mathrm{~cm}(\lambda / 6)$ \\
\hline Panjang lengan dipol $(\mathrm{w} 1=\mathrm{w} 2)$ & $4,175 \mathrm{~cm}(0.199 \lambda)$ \\
\hline Sudut antara lengan dipol $(\theta)$ & $150^{\circ}$ \\
\hline
\end{tabular}

\section{HASIL DAN DISKUSI}

Perangkat lunak berbasis kode elektromagnetik numerik digunakan untuk mensimulasikan semua kombinasi parameter tersebut. Simulasi dilakukan dengan parameter Perfect Ground dan impedansi $50 \mathrm{ohm}$ pada titik terminal. Simulasi menggunakan kawat konduktor dengan diameter enam milimeter untuk membangun geometri antena.

Gambar 2 memperlihatkan variasi SWR terhadap perubahan sudut diantara lengan dipol dan ketinggian antena terhadap tanah. Dapat diamati bahwa SWR paling rendah diperoleh ketika antena diletakkan pada ketinggian $\lambda / 6$ dari permukaan tanah, dengan sudut antara lengan dipol sebesar $150^{\circ}$. Panjang lengan dipol ketika SWR minimum ini adalah $4,175 \mathrm{~cm}$, sehingga menjadi salah satu parameter geometri antena yang diusulkan. Geometri ini telah disimulasikan, dimana frekuensi puncak diperoleh pada frekuensi $1420 \mathrm{MHz}$ dengan SWR sebesar 1,008. Nilai SWR dibawah 2 (Bandwidth) yang diperoleh adalah $1356 \mathrm{MHz}$ sampai dengan $1500 \mathrm{MHz}$.

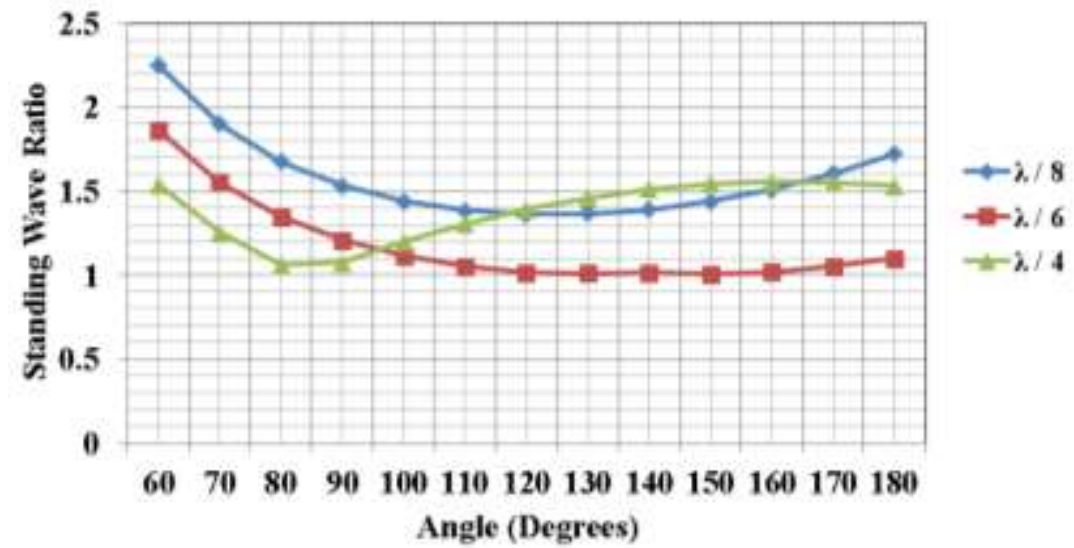

Gambar 2. Variasi SWR terhadap sudut antara lengan dipol dan ketinggian antena dari tanah pada antena berbentuk V yang diusulkan

Desain yang ditampilkan pada Gambar 1 dan Tabel 1 telah diimplementasikan seperti yang diperlihatkan pada Gambar 3. Sebagai elemen peradiasi, digunakan batang aluminium dengan diameter sebesar $6 \mathrm{~mm}$. Akrilik digunakan sebagai bahan penyangga/tiang antena, sedangkan untuk membuat kondisi yang menyerupai Perfect Ground, sebuah pelat aluminium diletakkan dibawah antena dan digunakan juga sebagai fondasi tempat meletakkan prototipe antena tersebut. Nilai return loss prototipe ini telah diukur dengan menggunakan Vector Network Analyzer (VNA), seperti yang ditunjukkan pada Gambar 4. Frekuensi operasi puncak diperoleh pada $1430 \mathrm{MHz}$, berbeda $0,7 \%$ dibandingkan dengan frekuensi yang diinginkan yaitu 1420MHz. Pada frekuensi puncak ini, nilai return loss yang diperoleh adalah $-23,58 \mathrm{~dB}$, berkorespondensi dengan nilai SWR sekitar 1,14. Bandwidth yang diperoleh sekitar 4,9\%. SWR pada frekuensi $1420 \mathrm{MHz}$ masih cukup rendah, yaitu 1,26. Gambar 5 memperlihatkan perbandingan antara hasil simulasi dengan hasil pengukuran. 


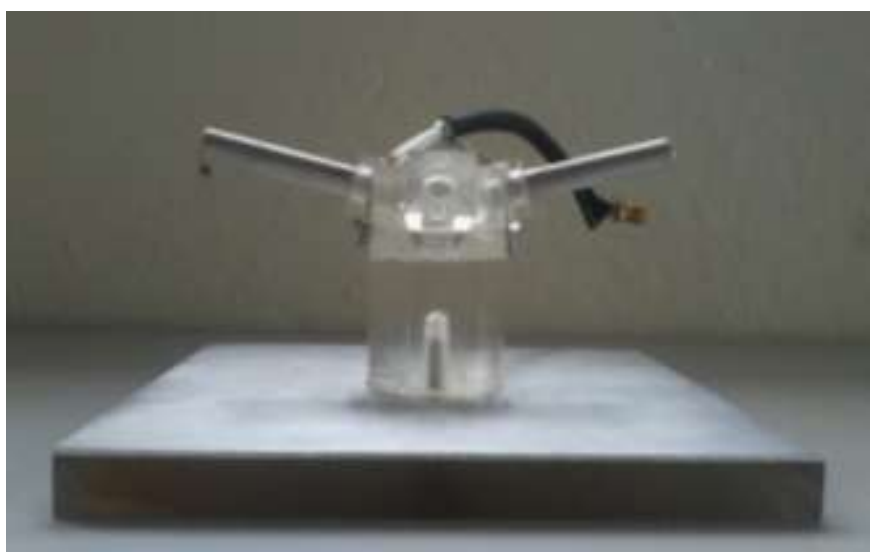

Gambar 3. Prototipe antena $1420 \mathrm{MHz}$

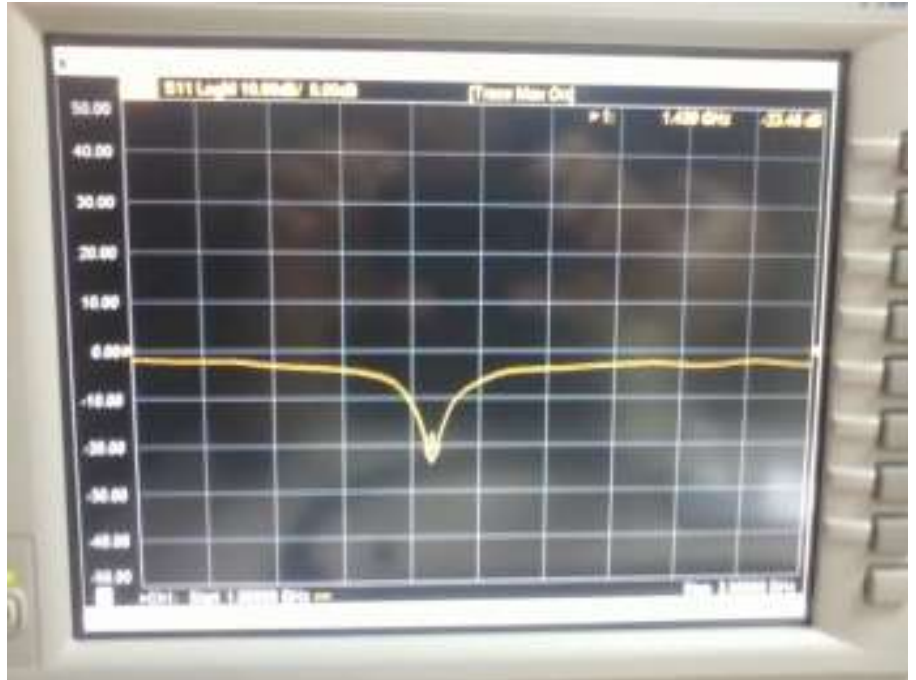

Gambar 4. Pengukuran return loss prototipe antena berbentuk V

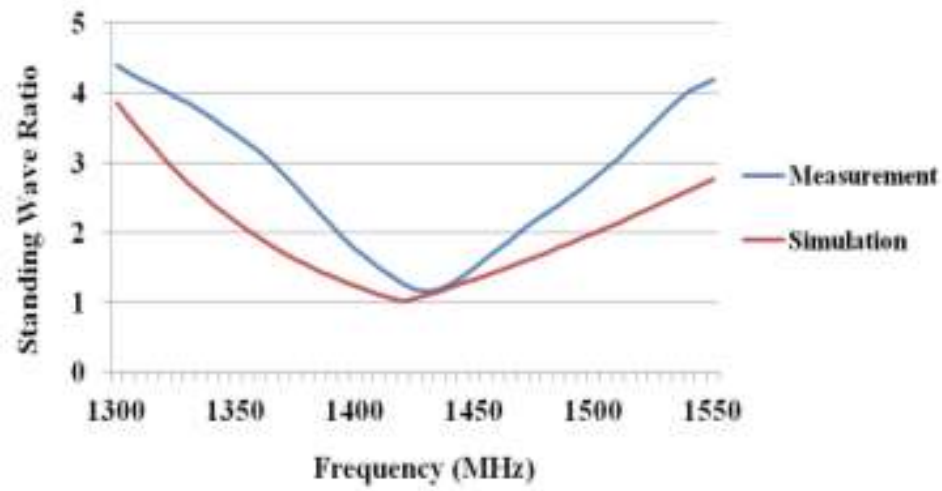

Gambar 5. Perbandingan hasil simulasi dan pengukuran SWR antena berbentuk V

Karena keterbatasan ukuran platform turn-table yang tersedia, prototipe antena tersebut tidak dapat diukur di dalam anechoic chamber. Oleh karena itu, pola radiasi antena ini hanya disimulasikan dengan menggunakan perangkat lunak, seperti yang diperlihatkan pada Gambar 6. 
Lebar berkas (beamwidth) yang diperoleh adalah sekitar $66^{\circ}$ pada sumbu medan listrik (E-Field) dan $106^{\circ}$ pada sumbu medan magnet $(H$-Field) dengan nilai gain maksimum sebesar $8,32 \mathrm{dBi}$ pada arah zenit (tegak lurus ke atas).

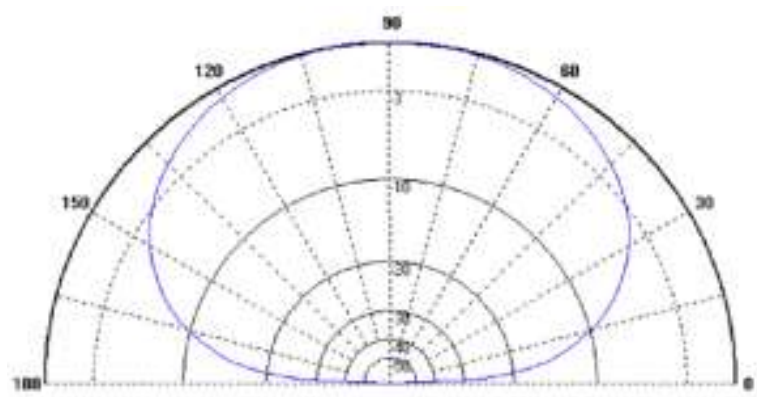

Gambar 6. Pola radiasi antena berbentuk V yang diusulkan (H-Field)

Prototipe antena ini sudah diujicoba dengan menggunakan perangkat penerima (receiver/radio spectrograph) yang bekerja pada frekuensi $45 \mathrm{MHz}$ hingga $870 \mathrm{MHz}$. Karena frekuensi kerja antena berada diluar rentang frekuensi receiver, maka digunakan modul downconverter yang mengubah spektrum frekuensi $1065 \mathrm{MHz}-1759 \mathrm{MHz}$ menjadi $750 \mathrm{MHz}-65 \mathrm{MHz}$. Salah satu hasil uji coba dengan menggunakan prototipe antena ini ditampilkan pada Gambar 7. Objek yang diamati pada saat uji coba tersebut adalah matahari.

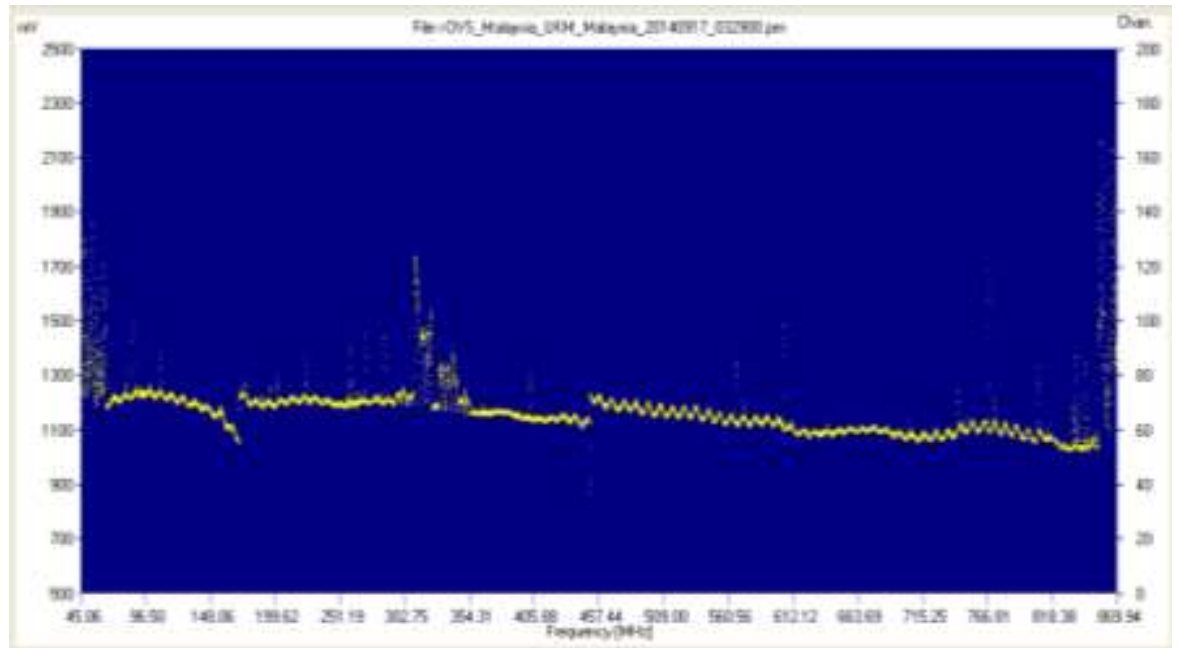

Gambar 7. Sinyal matahari yang diperoleh pada saat uji coba

\section{KESIMPULAN}

Artikel ini menyajikan hasil pengukuran sebuah antena berbasis dipol berbentuk $\mathrm{V}$ yang dirancang untuk digunakan pada sistem teleskop radio $21 \mathrm{~cm}$. Pengukuran menunjukkan hasil yang berkesesuaian dengan nilai yang diperoleh melalui simulasi. Frekuensi operasi puncak diperoleh pada $1430 \mathrm{MHz}$ (tingkat kesalahan sekitar $0,7 \%$ terhadap frekuensi yang diinginkan, yaitu 1420MHz), dengan SWR sekitar 1,14 (berkorespondensi dengan return loss sebesar -23,58 dB) dan bandwidth sekitar 4,9\%. SWR pada frekuensi $1420 \mathrm{MHz}$ masih sangat rendah, yaitu 1,26. 
Berdasarkan pola radiasinya yang lebar dan puncak gain pada arah zenith, antena ini sesuai untuk digunakan sebagai feed pada antena reflektor maupun sebagai elemen pada sistem transient array.

\section{DAFTAR PUSTAKA}

[1] Wielebinski, R., Kellermann, K.I. and Orchiston, W. 2007. The Early History of European Radio Astronomy. Astronomische Nachrichten. 328 375-446.

[2] CRAF (Committee on Radio Astronomy Frequencies). 2005. CRAF Handbook for Radio Astronomy 3rd ed.: European Science Foundation.

[3] Wolfe, S.A., Lockman, F.J. and Pisano, D.J. 2016. Sensitive $21 \mathrm{~cm}$ Observations of Neutral Hydrogen in the Local Group Near M31. The Astrophysical Journal. 816:2 81-93.

[4] Pritchard, J.R. and Pierpaoli, E. 2009. Neutrino Mass from Cosmological $21 \mathrm{~cm}$ Observations. Nuclear Physics B - Proceedings Supplements. 188 31-33.

[5] Haystack MIT. SRT. [Online] Available: http://www.haystack.mit.edu/edu/undergrad/srt/oldsrt.html [Diakses pada tanggal 2 November 2016]

[6] Holmdel. 2016. Holmdel Horn Antenna. [Online] Available: http://www.atlasobscura.com/places/holmdel-horn-antenna [Diakses pada 2 November 2016]

[7] Golap, K., Shankar, N.U., Sachdev, S., Dodson, R. \& Sastry, Ch.V. 1998. A Low Frequency Radio Telescope at Mauritius for a Southern Sky Survey. Journal of Astrophysics and Astronomy. 19 35-53.

[8] De Vos, M., Gunst, A.W. and Nijboer R. 2009. The LOFAR Telescope: System Architecture and Signal Processing. Proceedings of the IEEE. 97:8 1431-1437.

[9] Anwar, R., Islam, M.T., Misran, N., Gopir, G. and Yatim, B. 2009. Development of a Multiband VHF Antenna for Low-Frequency Transient Radio Telescope. Journal of Electromagnetics, Waves and Applications (JEMWA). 23 1843-1854. ISSN: 0920-5071.

[10] Anwar, R., Islam, M.T., Misran, N., Gopir, G., Yatim, B., and Asillam, M.F. 2014. Effect of Parasitic Element on $408 \mathrm{MHz}$ Antenna for Radio Astronomy Application. International Journal of Antennas and Propagation. Volume 2014, Article ID 614952.

[11] Ishak, A.N., Anwar, R., Islam, M.T., Misran, N., Yatim, B., and Asillam, M.F. 2013. Optimization of Dipole-Based Antenna for $21 \mathrm{~cm}$ Line Observation. 2013 International Conference on Space Science and Communication (IconSpace 2013) Melaka, Malaysia, 1 3 July 2013, pp. 134-136. 